\title{
Pancreaticoduodenectomy for pancreas carcinoma occurring in the annular pancreas: report of a case
}

\author{
Hiromichi Kawaida $^{1}$ Hiroshi Kono ${ }^{1}$ Mitsuaki Watanabe ${ }^{1}$ Akira Maki ${ }^{1}$. \\ Hidetake Amemiya $^{1}$ - Masanori Matsuda ${ }^{1}$ Hideki Fujii ${ }^{1} \cdot$ Mitsuharu Fukasawa $^{2}$. \\ Ei Takahashi ${ }^{2} \cdot$ Katsuhiro Sano $^{3}$. Tomohiro Inoue ${ }^{4}$
}

Received: 30 April 2015/Accepted: 9 June 2015/Published online: 8 July 2015

(C) The Author(s) 2015. This article is published with open access at Springerlink.com

\begin{abstract}
The annular pancreas is a rare congenital anomaly in which a ring of the pancreas parenchyma surrounds the second part of the duodenum. Malignant tumors are extremely rare in patients with an annular pancreas. A 64-year-old man presented with appetite loss and vomiting. Abdominal contrast-enhanced computed tomography (CT) indicated pancreas parenchyma surrounding the second part of the duodenum, and a hypovascular area occupying lesion in the annular pancreas. Subtotal stomach-preserving pancreaticoduodenectomy was performed. Histopathology showed pancreatic carcinoma occurring in the complete annular pancreas.
\end{abstract}

Keywords Annular pancreas - Pancreas carcinoma . Pancreaticoduodenectomy

\section{Introduction}

An annular pancreas is a rare congenital anomaly in which the second part of the duodenum is surrounded by a ring of pancreas parenchyma. It was first described by Tiedemann

Hiromichi Kawaida

hrkawaida@yahoo.co.jp

1 First Department of Surgery, Faculty of Medicine, University of Yamanashi, 1110 Shimokato, Chuo, Yamanashi 409-3898, Japan

2 First Department of Internal Medicine, Faculty of Medicine, University of Yamanashi, Chuo, Japan

3 Department of Radiology, Faculty of Medicine, University of Yamanashi, Chuo, Japan

4 Department of Human Pathology, Faculty of Medicine, University of Yamanashi, Chuo, Japan
[1] in 1818 and was termed "annular pancreas" by Ecker in 1862 [2]. In adults, annular pancreas has been known to be associated with peptic ulceration, duodenal obstruction, pancreatitis, and obstructive jaundice. The presence of the annular pancreas was reported in three of 20,000 autopsies [3] and three of 24,519 surgical cases [4]. Malignant tumors are extremely rare in patients with an annular pancreas (Table 1). Herein, we report a case of pancreas carcinoma occurring in the annular pancreas.

\section{Clinical summary}

A 64-year-old man was admitted to University of Yamanashi Hospital for complaint of abdominal pain and vomiting. On admission, physical examination revealed no anemia and jaundice in the conjunctiva, and no tenderness and no mass in the abdomen. Laboratory findings showed elevated alkaline phosphatases, 898 U/1 (100-310), aspartate aminotransferase, $67 \mathrm{U} / 1(<30 \mathrm{U} / 1)$, alanine aminotransferase, $144 \mathrm{U} / 1(<35 \mathrm{U} / \mathrm{l})$ and hemoglobin A1c, $7.7 \%$ $(<6.2 \%)$. Furthermore, carbohydrate antigen 19-9 was elevated to $158 \mathrm{U} / \mathrm{ml}(<37 \mathrm{U} / \mathrm{ml})$; however, carcinoembryonic antigen was within the normal range.

Upper gastrointestinal radiology and esophagogastroduodenoscopy showed stenosis at the descending part of the duodenum. Endoscopic ultrasonography showed a hypoechogenic mass measuring $21 \times 13 \mathrm{~mm}$ in the pancreas head. In addition, abdominal enhanced-CT revealed the pancreatic parenchyma encircling the descending part of the duodenum, and a hypovascular mass lesion was observed in the annular pancreas (Fig. 1a, b). Magnetic resonance cholangiopancreatography (MRCP) showed the pancreatic duct in the annular pancreas encircling the duodenum connected with the common bile duct (CBD) 
Table 1 Reported cases of an annular pancreas with carcinoma of the pancreas

\begin{tabular}{|c|c|c|c|c|c|c|c|c|c|c|}
\hline Case & Author & $\begin{array}{l}\text { Age } \\
\text { (years) }\end{array}$ & Gender & Symptoms & Location & $\begin{array}{l}\text { Size } \\
(\mathrm{cm})\end{array}$ & Operation & $\begin{array}{l}\text { TNM } \\
\text { classification }\end{array}$ & $\begin{array}{l}\text { Outcome } \\
\text { (months) }\end{array}$ & Diagnosis of AP \\
\hline 1 & $\begin{array}{l}\text { Matsusue } \\
{[20]}\end{array}$ & 53 & $\mathrm{~F}$ & $\begin{array}{l}\text { Abdominal discomfort, } \\
\text { spiky fever }\end{array}$ & Head & $3 \times 4$ & $\mathrm{TP}$ & IB & 15 , alive & $\begin{array}{l}\text { Laparotomy } \\
\text { intraoperation }\end{array}$ \\
\hline 2 & Yasui [20] & 54 & M & $\begin{array}{l}\text { Dark urine, repeated } \\
\text { vomiting }\end{array}$ & Head & $2.5 \times 3.0$ & PPPD & IIA & ND & $\begin{array}{l}\text { Laparotomy } \\
\text { intraoperation }\end{array}$ \\
\hline 3 & $\begin{array}{c}\text { Kamisawa } \\
\text { [12] }\end{array}$ & 71 & $\mathrm{~F}$ & Epigastralgia & Body & 5 & Inoperable & IV & 4, death & $\begin{array}{l}\text { Upper } \\
\text { gastrointestinal } \\
\text { ERCP }\end{array}$ \\
\hline 4 & Kfir [21] & 52 & $\mathrm{~F}$ & $\begin{array}{l}\text { Epigastric abdominal } \\
\text { pain }\end{array}$ & Diffuse & ND & $\mathrm{TP}$ & IIA & 9 , death & ERCP \\
\hline 5 & $\begin{array}{c}\text { Cholet } \\
{[15]}\end{array}$ & 88 & $\mathrm{~F}$ & Jaundice & Head & $4.5 \times 2.5$ & Inoperable & ND & 3 , death & ERCP, MRCP \\
\hline 6 & $\begin{array}{l}\text { Present } \\
\text { case }\end{array}$ & 64 & M & $\begin{array}{l}\text { Abdominal pain } \\
\text { vomiting }\end{array}$ & $\begin{array}{l}\text { Head } \\
\text { (AP) }\end{array}$ & $2.1 \times 1.3$ & SSPPD & IIB & 16, alive & CT \\
\hline
\end{tabular}

$T P$ total pancreatectomy, $P P P D$ pylorus preserving pancreaticoduodenectomy, SSPPD subtotal stomach preserving pancreaticoduodenectomy, $N D$ not defined, $E R C P$ endoscopic retrograde cholangiopancreatography, $M R C P$ Magnetic resonance cholangiopancreatography, $C T$ computed tomography
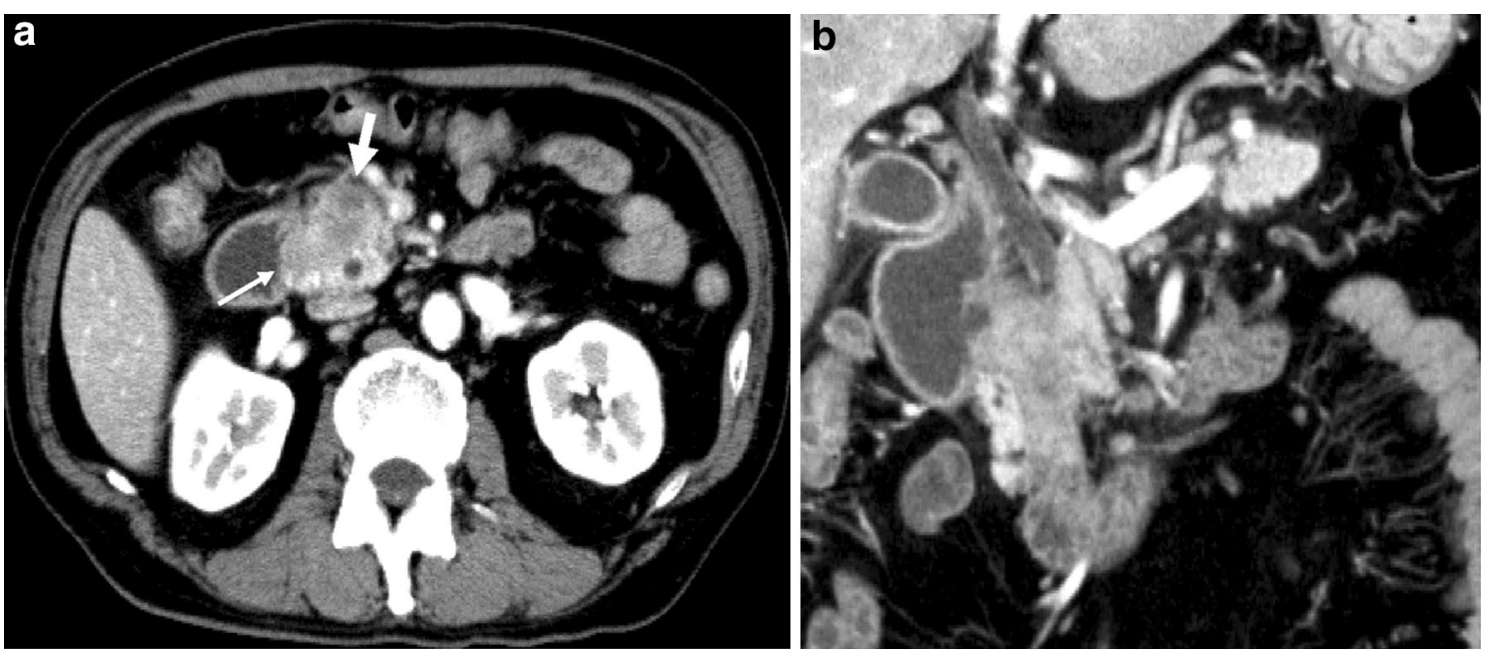

Fig. 1 a Enhanced CT shows pancreatic parenchyma encircling the descending part of the duodenum (thin arrow); and b low density lesion is observed in the annular pancreas (thick arrow)

(Fig. 2). Endoscopic ultrasound-guided fine needle aspiration biopsy (EUS-FNA) was performed and the cytologic findings showed class IV, strongly suspicious of adenocarcinoma.

The patient underwent subtotal stomach preserving pancreaticoduodenectomy with dissection of the regional lymph nodes. At laparotomy, the pancreas parenchymal tissue was surrounding the descending part of the duodenum, and the tumor was located in the annular pancreas (Fig. 3). Neither liver metastasis nor peritoneal dissemination was found. Cholangiopancreatography of the resected specimen showed the pancreatic duct in the annular pancreas, connected to the CBD; it could not show the duct of Wirsung (Fig. 4a, b). A pathological examination showed well-differentiated adenocarcinoma with regional lymph node metastasis (TNM classification: T2N1M0, Stage IIB) (Fig. 5). The postoperative course was uneventful, and the patient was discharged at 26 days after surgery.

\section{Discussion}

The annular pancreas is a rare anatomical anomaly, in which the pancreas parenchyma surrounds the descending part of the duodenum. Most of adult cases become symptomatic at ages between 30 and 50 years [5], and males occupied $65.1 \%$ of total cases [6]. The predominant 


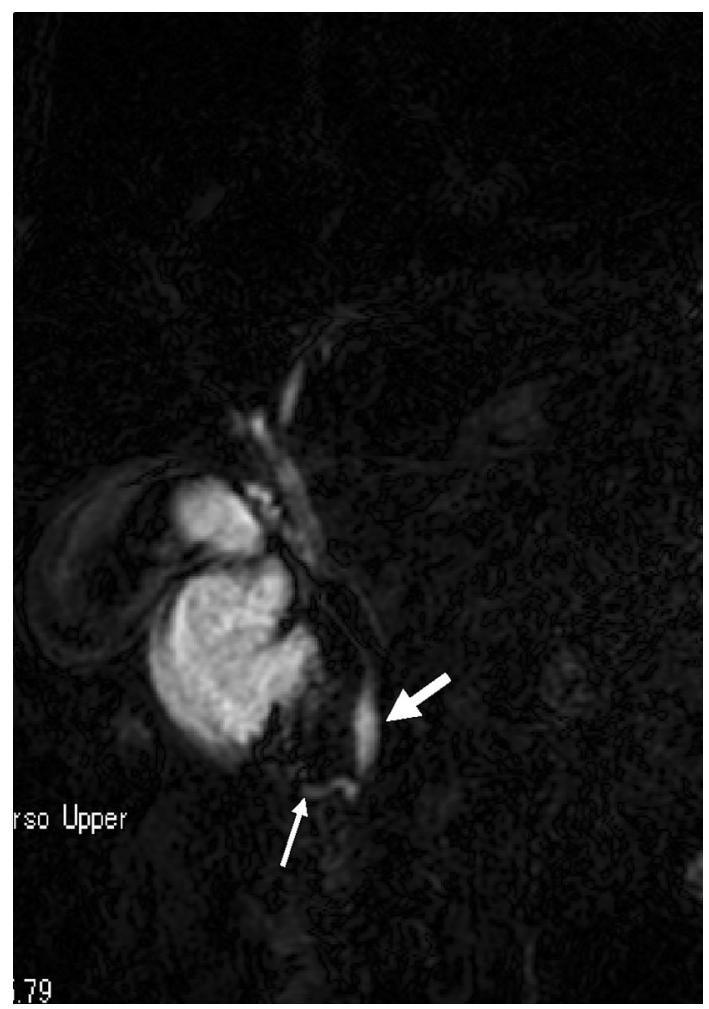

Fig. 2 MRCP shows the duct of the annular pancreas (thin arrow) connects with the common bile duct (thick arrow)

symptoms of the annular pancreas are epigastric pain, postprandial fullness, vomiting, and weight loss in adults $[7,8]$. Furthermore, the main complications of the annular pancreas are peptic ulcers, cholecystolithiasis and pancreatitis [9].

Previously, two hypotheses have been proposed to explain the etiology of the annular pancreas: Lecco's theory attributes it to adhesion of the right ventral angle to the duodenal wall [10], and Baldwin's theory considers it to involve persistence of the left ventral bud [11]. Although Lecco's theory is supported by many reports, not all cases can be explained by only this hypothesis.

The presence of the annular pancreas was reported in three of 20,000 autopsies [3] and three of 24,519 surgical cases [4]. Although the annular pancreas is rare, it has been recently recognized frequently due to progression of diagnostic imaging devices. Among patients undergoing endoscopic retrograde cholangiopancreatography (ERCP), approximately one in 1000 examined cases was found to have the annular pancreas [3, 12]. In these cases, ERCP may not always be successful, due to technical difficulty in some cases, particularly in cases with the duodenal ulcer and/or stenosis of the descending part of the duodenum [13]. In most cases, multi-slice CT shows the circumferential pancreatic parenchyma around the descending part of the duodenum [13, 14]; however, in some cases, this

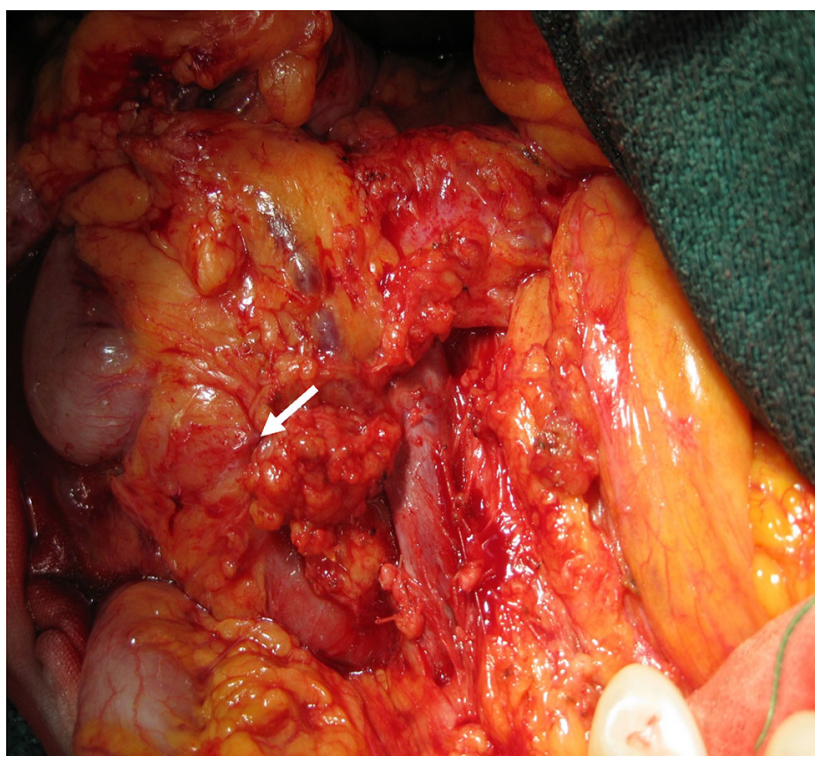

Fig. 3 Intraoperative photograph shows the annular pancreas surrounded the descending part of the duodenum (thick arrow)

imaging method may lead to misinterpretation as a thickening of the duodenum [15]. With this in mind, magnetic resonance imaging (MRI) and MRCP are useful for understanding anomalies observed in the pancreatic anatomy $[13,15,16]$.

The efficacy of endoscopic ultrasonography in the annular pancreas has also been reported, as for less-invasive imaging devices [16, 17]. In addition, EUS-FNA is a highly accurate method for the histological diagnosis of pancreatic carcinoma [18, 19]. In the present case, a definitive diagnosis was possible without operation by EUS-FNA.

Yogi et al. classified six variants of the ductal anatomy in patients with annular pancreas [9]. The most frequent type is type I, in which the main pancreatic duct (MPD) in the annular pancreas opens into the duct of Wirsung. In the second most frequent type, the MPD is encircled the duodenum (type II). The other four types of anomaly are uncommon. The present case is presumed to be type IV, in which the MPD in the annular pancreas opens into the CBD without the duct of Wirsung.

Among the cases reported in the literature, only five have been reported to involve the annular pancreas $[12,15$, 20-22]. Among them, three cases were located in the pancreas head, one case in the pancreas body, and one case existed diffusely in the pancreas; however, there were no cases with existing carcinoma in the annular pancreas, except the present case.

In conclusion, to our knowledge, the present report is the first clinical case of pancreatic carcinoma occurring from the annular pancreas. In patients with the annular pancreas, the possibility of coexistent malignancy in the pancreato- 
Fig. 4 a The resected specimen cholangiopancreatography shows the duct of the annular pancreas (thin arrow) encircling the duodenum connected with the CBD (thick arrow); and b could not show the duct of Wirsung (thin arrow:

Santorini). c An illustration
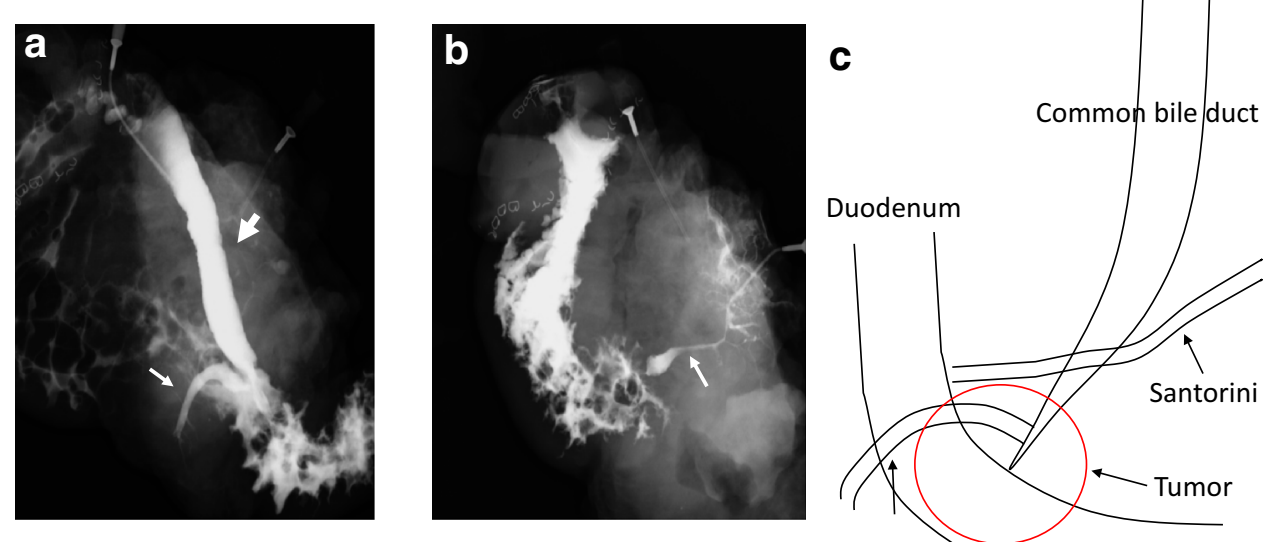

The duct of the annular pancreas

human experimentation (institutional and national) and with the Helsinki Declaration of 1975, as revised in 2008(5).

Informed Consent: Informed consent was obtained from all patients included in the study.

Open Access This article is distributed under the terms of the Creative Commons Attribution 4.0 International License (http://creativecommons.org/licenses/by/4.0/), which permits unrestricted use, distribution, and reproduction in any medium, provided you give appropriate credit to the original author(s) and the source, provide a link to the Creative Commons license, and indicate if changes were made.

\section{References}

1. Tiedemann F. Uber die Verschiedenheiten des Ausfuhrungsganges der Bauchspeicheldruse bei den Menschen und Saugetier, thereen. Dtsch Arch Physiol. 1818;4:403.

2. Ecker A. Bildungsfehler des Pancreas und des Herzens. Z Rat Med. 1862;14:354.

3. Ravitch MM, Woods AC Jr. Annular pancreas. Ann Surg. 1950;132(11):16-27.

4. Theodorides T. Pancreas annulare. J Chir. 1964;87:445-62.

5. Chen YC, Yeh CN, Tseng JH. Symptomatic adult annular pancreas. J Clin Gastroenterol. 2003;36:446-50.

6. Kiernan PD, ReMine SG, Kiernan PC, et al. Annular pancreas. Arch Surg. 1980;115:46-50.

7. Ladd AP, Madura JA. Congenital duodenal anomalies in the adult. Arch Surg. 2001;136:576-84.

8. Urayama S, Kozarek R, Ball T, et al. Presentation and treatment of annular pancreas in an adult population. Am J Gastroenterol. 1995;90:995-9.

9. Yogi Y, Shibue T, Hashimoto S. Annular pancreas. J Gastroenterol. 1987;22:91-9.

10. Lecco TM. Zur Morphologie des Pankreas Annulare. Sitzungsb Akad Wissensch. 1910;119:391-406.

11. Baldwin WM. A specimen of annular pancreas.Anat Rec. 1910;4:299-304.

12. Terymi K, Ikuo T, Tomoaki I, et al. Annular pancreas associated with carcinoma in the dorsal part of pancreatic divisum. Int $\mathbf{J}$ Pancreatol. 1995;17:207-11.

13. Yazawa N, Imaizumi T, Furukawa D, et al. An annular pancreas associated with carcinoma of the papilla of Vater:report of a case. Surg Today. 2012;42:497-501. 
14. Enrico B, Silke P, Tatjana V, Daniel O, Oleg H. Annular pancreas associated with duodenal carcinoma. World $\mathrm{J}$ Gastroenterol. 2010;16(25):3206-10.

15. Cholet F, Bideau K, Nonent M, et al. Coexistence of annular pancreas with carcinoma in the dorsal part of pancreas divisum:diagnostic value of magnetic resonance cholangiopancreatography. Abdom Imaging. 2004;29:703-6.

16. Yamaguchi Y, Sugiyama M, Sano Y, et al. Annular pancreas complicated by carcinoma of the bile duct: diagnosis by MR cholangiopancreatography and endoscopic ultrasonography. Abdom Imaging. 2003;28:381-3.

17. Davion T, Maunoury V, Lescanne-Darchis I, et al. Annular pancreas: ultrasound endoscopy too. Gastroenterol Clin Biol. 1996;20:218-9.

18. Naveen B, Krishna MBBS, Jennifer L, et al. Diagnostic Value of EUS-FNA in patients suspected of having pancreatic cancer with a focal lesion on CT Scan/MRI but without obstructive jaundice. Pancreas. 2009;38(6):625-30.

19. Ryozawa S, Kitoh H, Gondo T, et al. Usefulness of endoscopic ultrasound-guided fine-needle aspiration biopsy for the diagnosis of pancreatic cancer. J Gastroenterol. 2005;40:907-11.

20. Matsusue S, Kashihara S, Koizumi S. Pancreatectomy for carcinoma of the head of the pancreas associated with multiple anomalies including the preduodenal portal vein. Jpn J Surg. 1984;14(5):394-8.

21. Yasui A, Nimura Y, Kondou S, Komiya J. Duodenal obstruction due to annular pancreas associated with pancreatic head carcinoma. Hepatogastroenterology. 1995;42:1017-22.

22. Ben-David K, Falcone RA Jr, Matthews JB. Diffuse pancreatic adenocarcinoma identified in an adult with annular pancreas. J Gastrointest Surg. 2004;8:565-8. 